\title{
Colo-rectum: why do we not find diminutive sessile serrated polyp?
}

\section{(ㄷ)(요 $\odot$}

\author{
Authors \\ Mathieu Pioche ${ }^{1}$, Daizen Hirata ${ }^{2}$, Valérie Hervieu ${ }^{3}$, Yasushi Sano ${ }^{2}$ \\ Institutions \\ 1 Hepatogastroenterology division, Edouard Herriot \\ Hospital, Lyon, France \\ 2 Endoscopy division, Sano's Hospital, Maikoshi, Japan \\ 3 Histology department, Hospices civils de Lyon, France \\ submitted 29.5.2019 \\ accepted after revision 3.6.2019 \\ Bibliography \\ Endoscopy International Open 2019; 07: E1049-E1050 \\ (c) Georg Thieme Verlag KG Stuttgart · New York \\ elSSN 2196-9736 \\ Corresponding author \\ Mathieu Pioche, MD, PHD, Service de gastro-entérologie et \\ d'endoscopie digestive, Pavillon L, Hôpital Edouard Herriot, \\ 5 place d'Arsonval 69437 Lyon, France \\ Fax: +33472110147 \\ mathieu.pioche@chu-lyon.fr
}

DOI https://doi.org/10.1055/a-0959-6030 |
Sessile serrated adenoma/polyps (SSA/Ps) are early precursor lesions in the serrated neoplasia pathway. Some of these lesions can rapidly become dysplastic or invasive carcinomas that exhibit high lymphatic invasion and lymph node metastasis potentials. Detecting serrated lesions, including SSA/Ps with and without dysplasia/carcinoma, is challenging. Unlike hyperplastic polyps, SSA/Ps are more frequently larger than $5 \mathrm{~mm}$, and the question raised here is whether diminutive Serrated lesions $(<5 \mathrm{~mm})$ really exist?

Of course, detection of these SSAP despite virtual chromoendoscopy is much more difficult than detection of adenomas. This may be partly explained by the minimum size requirement of $5 \mathrm{~mm}$ for detection of discrete mucosal and vascular changes. On the other hand, our endoscopes have improved considerably [1], our capacities to detect small lesions have also improved, indigo carmine makes it easier to detect very small abnormal areas and yet, it must be said that we do not often find diminutive SSAP, including in sessile serrated polyposis. How can this inconsistency be explained?

Is the development of SSAP so rapid initially with intense cell multiplication that the period during which the lesions are $<5 \mathrm{~mm}$ is too short for us to detect them lesions? When several colonoscopies are performed successively in patients, there is no major increase in the size of the lesions in a few months, and very rapid extension initially followed by a slow-down in growth is not supported by histological findings.

Is there initial lateral development of the deep lesion of the crypts before the anomaly appears on the surface of the glands? For this second hypothesis, we would then have to find histologically larger lesions at depth than at the mucosal surface, resembling an iceberg. However, cell division in SSAPs occurs at the bottom of the crypt, lesion size at the deep part of the mucosa is identical to the surface area ( $\triangleright$ Fig. 1c, $\triangleright$ Fig. 1d).

Finally, there do not seem to be any histological arguments to support deep initial development of the lesion, therefore, it must be recognized that these lesions exist but our ability to detect them is compromised. First, at an early stage, a diminutive SSAP appears thin and therefore translucent, allowing the vasculature of the underlying colonic wall [2] to be seen through that transparency ( $\bullet$ Fig. 1). In such cases, interruption of the background vascular relief, with its subtle color and texture anomalies, cannot be relied upon as a way for the eye to detect a lesion. The lesion presented here is barely visible because it is so thin ( $\mathbf{F i g . 1}$ ). Indigo carmine dye could improve detection of such small lesions, as previously demonstrated in sessile serrated polyposis, and virtual chromoendoscopy can help characterize tiny lesions ( $>$ Fig.2) [3].

In addition, the small amount of serrated glands in a diminutive lesion with a small surface area is most likely correlated with low mucus secretion ( $\triangleright$ Fig.3), even though the mucus cap has become a criterion for detecting these lesions when deposits adhering to the wall against gravity are identified. Finally, these tiny lesions pose characterization problems because presence of the diagnostic criteria of the WASP classification [4] (indistinct edges, cloudy appearance, black spot at the bottom of the crypts) are less likely to be present than in large lesions.

In conclusion, because we were entrusted with writing of this editorial, we have detected multiple diminutive SSAP that we didn't believe we were finding before. They therefore exist 


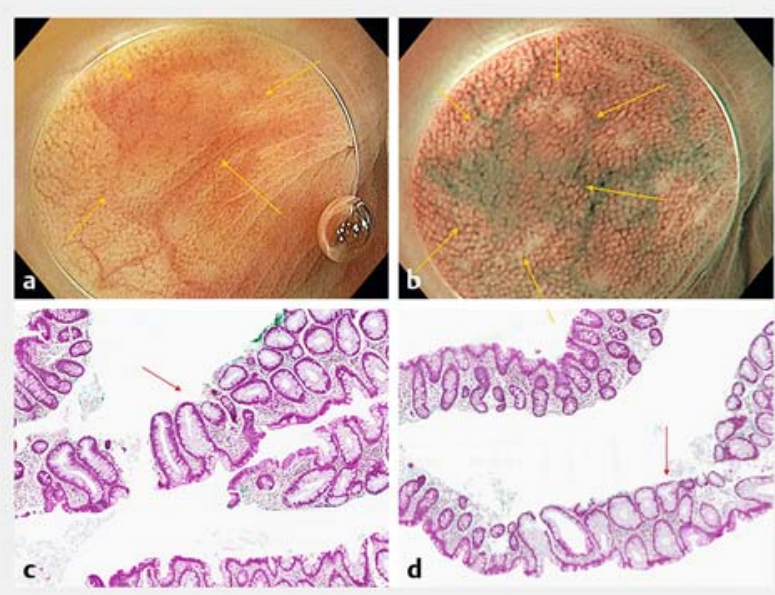

- Fig. 1 Diminutive SSAP with thin aspect. a White light imaging with subtle color and texture anomalies. b NBI imaging with thin aspect. c, $\mathbf{d}$ Histological confirmation of the serrated component.
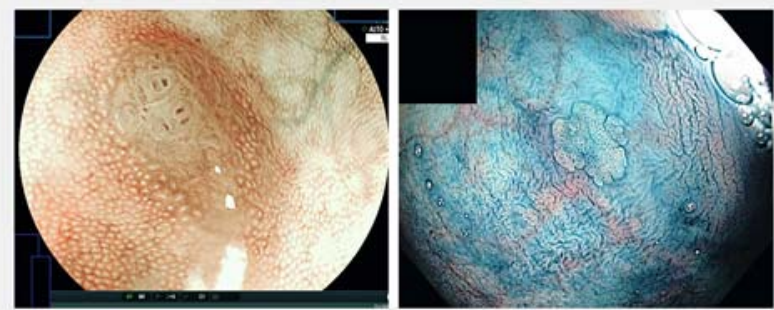

Fig. 2 Diminutive SSAP in BLI and Indigo carmine dye.

but represent a huge detection challenge and could become a quality criterion for defining super-detecting endoscopists in the future.

\section{Competing interests}

Dr. Pioche has received fee for training people in optical diagnosis by Olympus.

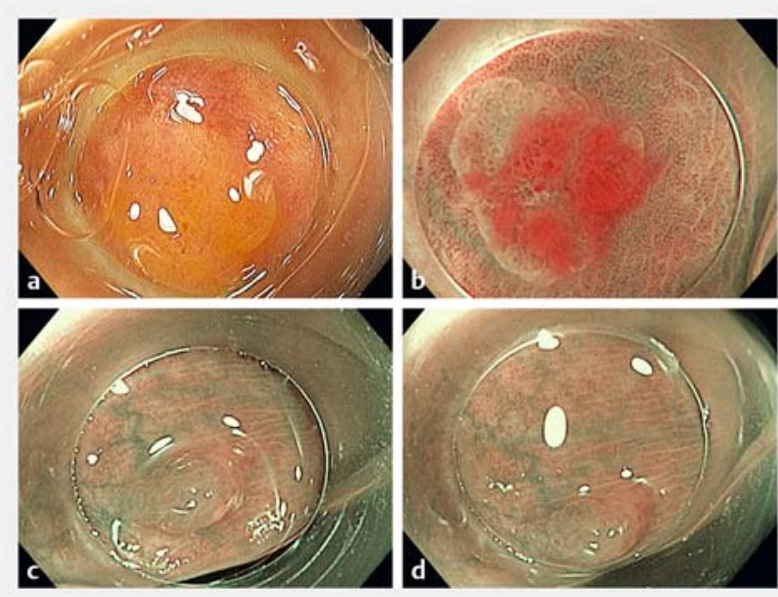

- Fig. 3 Different examples of diminutive SSAP. a,b White light and NBI imaging of a 5-mm SSAP with low mucus production. c, d SSAP of $3 \mathrm{~mm}$ without any mucus cap.

\section{References}

[1] Pioche M, Denis A, Allescher H-D et al. Impact of 2 generational improvements in colonoscopes on adenoma miss rates: results of a prospective randomized multicenter tandem study. Gastrointest Endosc 2018; 88: $107-116$

[2] Uraoka T, Saito Y, Ikematsu H et al. Sano's capillary pattern classification for narrow-band imaging of early colorectal lesions. Dig Endosc 2011; 23: (Suppl. 01): 112-115

[3] López-Vicente J, Rodríguez-Alcalde D, Hernández L et al. Panchromoendoscopy increases detection of polyps in patients with serrated polyposis syndrome. Clin Gastroenterol Hepatol 2018: doi:10.1016/j. cgh.2018.10.029 [Epub ahead of print]

[4] IJspeert JEG, Bastiaansen BAJ, van Leerdam ME et al. Development and validation of the WASP classification system for optical diagnosis of adenomas, hyperplastic polyps and sessile serrated adenomas/ polyps. Gut 2016; 65: $963-970$ 